\title{
Farmers' Satisfaction of Rural Facilities and Its Influencing Indicators: A Case Study of Sichuan, China
}

\author{
Yibin Ao, ${ }^{1,2}$ Jiayue Li, ${ }^{1}$ Yan Wang, ${ }^{3}$ Changjiang Liu, ${ }^{1}$ and Shuhong $\mathrm{Xu}^{4}$ \\ ${ }^{1}$ College of Environment and Civil Engineering, Chengdu University of Technology, Chengdu, Sichuan 610059, China \\ ${ }^{2}$ Business School, Sichuan University, Chengdu, Sichuan 610065, China \\ ${ }^{3}$ Department of Engineering Management, Sichuan College of Architectural Technology, Deyang, Sichuan 618000, China \\ ${ }^{4}$ School of Civil and Architecture Engineering, Zhengzhou University of Aeronautics, Zhengzhou, Henan 450015, China
}

Correspondence should be addressed to Jiayue Li; 13688176916@163.com

Received 2 January 2017; Revised 7 June 2017; Accepted 12 July 2017; Published 21 August 2017

Academic Editor: Anna M. Gil-Lafuente

Copyright (c) 2017 Yibin Ao et al. This is an open access article distributed under the Creative Commons Attribution License, which permits unrestricted use, distribution, and reproduction in any medium, provided the original work is properly cited.

\begin{abstract}
The disparity between construction targets and the real needs of farmers in the construction of rural facilities is a problem that has led to a failure in meeting farmers' demands. This paper investigates farmers' satisfaction and the influencing factors of rural facilities through factor analysis and logit regression model. This research led to three key findings: (1) overall satisfaction of farmers of rural facilities is below average level; (2) farmers' satisfaction is affected mainly by the horizontal comparison, road facilities, electricity and signal facilities, reconstruction of public toilets, irrigation facilities, cultural and recreational facilities, renovation of fuel and kitchen, healthy facilities, village planning and renovation, and income factor; (3) farmers' needs are shifting from production to life type. This paper is the foundation of further analysis of the effects of significant factors on farmers' satisfaction, providing a theoretical basis for the construction of "bottom-up" and "top-down" decision-making mechanism.
\end{abstract}

\section{Introduction}

Rural facilities construction is the foundation to ensure the comprehensive and rapid development of a rural economy and an important content of new rural construction. This construction also serves as the basis of a harmonious rural environment and overall affluence. Addressing problems in the construction of rural facilities is very crucial to the achievement of sustainable and coordinated urban and rural development. In recent years, some issues such as the incomplete supervision mechanism, limited financing channels, and lack of maintenance have become increasingly prominent with the rapid development of rural facilities. The real needs of farmers have been ignored all the time in the "top-down" planning pattern, resulting in a disconnection between construction targets and farmers' real demands.

With the aim of addressing the aforementioned disconnection, the researchers conducted a study on farmers' satisfaction of rural facilities and its significant indicators. On the basis of existing studies, the researchers selected evaluation factors of satisfaction assessment to create a comprehensive questionnaire that consists of whole satisfaction, satisfaction of each type of facilities, price attitude, horizontal comparison, vertical comparison, and basic information of interviewees. The reliability of the questionnaire was analyzed to test the validity of the survey. Factor analysis was then conducted to identify 15 factors and weights of indicators to calculate the satisfaction score. Finally, the logit regression model was used to analyze the 15 factors to test their effects on farmers' satisfaction.

\section{Literature Review}

At present, research related to rural facilities focuses mainly on sustainable development, existing problems and policy recommendations, and performance evaluation. Previous research on the sustainable development of infrastructure can be divided into research of evaluation index and the establishment of evaluation model. Many foreign studies related are about the sustainability of the whole life cycle 
of projects, while domestic Chinese research usually focuses on a certain stage to study the sustainable development of projects. With the deepening of research, the evaluation index system of infrastructure sustainability is constantly improved. Gan et al. [1] pointed out the lack of sustainable evaluation index in project decision-making stage in China and developed a questionnaire-based evaluation indicator system of infrastructure projects on the basis of sustainable development. Shen et al. [2] referenced 23 feasibility study reports and summarized 30 indicators to assess the sustainability of infrastructure projects. They selected $20 \mathrm{key}$ evaluation indicators using the fuzzy set theory and combined the expert scoring method to assess the sustainability of infrastructure projects. Subsequently, Bocchini et al. [3] combined resilience and sustainability in the assessment of infrastructure construction. Then, on the basis of previous studies, Boz and El-Adaway [4] proposed three innovative system-based benchmarks and a systematic framework to assess the sustainability of civil facilities projects. There are also other studies discussing project characteristics for specific types of infrastructure. For example, Anagnostopoulos and Vavatsikos [5] used spatial fuzzy analytic hierarchy process to help with the site selection of wastewater treatment system. Domingo [6] studied the complexity of medical and health projects and its effects on the generation of construction waste in the life cycle of projects, and Zhou and Liu [7] studied infrastructure projects from the perspective of microengineering, with the aim of creating a basic model to analyze sustainable construction and operation of infrastructure projects. With the deepening of study, the evaluation model of infrastructure sustainability is constantly improved. Not only is the sustainability of the project life cycle evaluated from the cost point of view, but also the overall sustainability of the project life cycle is evaluated by using the LCA model. Glick and Guggemos [8] combined LCC, LCA, and economic input-output to assess the sustainability of project. Parrish and Chester [9] developed an LCA based on the LCC for sustainability of infrastructure construction. Reza et al. [10] proposed a sustainability appraisal method of infrastructure named Emergy-Based Life Cycle Assessment. There are also studies on project forecasting based on previous studies. Zhi et al. [11] analyzed the driving factors of water demand in Beijing through IO-IOAT-SDA and systematically predicted the utilization of water resources in the following time of Beijing. In addition, some scholars have analyzed sustainability evaluation models. Ariaratnam et al. [12] compared four common underground public infrastructure construction methods from three aspects, namely, the environment, cost, and social influence. Torres-Machi et al. [13] performed a comparative analysis to study seven economic evaluation road project models. There are many studies on sustainable infrastructure assessment, and several evaluation systems and indices have been established in these studies; however, there are still no widely accepted criteria and system for assessing sustainability of infrastructure.

Performance evaluation mostly focuses on the efficiency of investment and farmers' satisfaction. Summing up previous studies, the construction of rural infrastructure in China has been continuously improved with government's continuous investment, which has promoted the development of rural economy and farmers economic status and living environment. However, the investment efficiency of rural infrastructure still has to be increased, and farmers' satisfaction on infrastructure construction is unsatisfactory. There is still great need for improvement in the performance of rural infrastructure construction. Many scholars have studied the investment in rural infrastructure by panel data. $\mathrm{Xu}$ and Wang $[14,15]$ analyzed the changes in investment efficiency of rural infrastructure and the trends in its changes in 29 provinces and cities. They studied stock of rural roads, running water facilities, and power facilities from 1990 to 2007 and calculated the contribution of infrastructure investment to farmers' income, expenditure, and the improvement of rural economy. Li et al. [16] established a fiscal performance evaluation system from economic, social, and ecological effects. The fiscal efficiency of 26 provinces (region) in China was analyzed on the basis of the evaluation system in their research. The investment efficiency of the projects has also been studied. Ansar et al. [17] analyzed project performance from the perspective of cost performance, schedule performance, and performance by collecting data for 95 railway and highway projects from 1984 to 2008. They found that, contrary to previous studies, the performance of Chinese infrastructure construction is unsatisfactory. They pointed out the necessity of changing the development pattern of China's infrastructure. Besides, scholars have also analyzed the performance of infrastructure investment through surveys. For example, Peng [18], Zhang and Wang [19], and Luo [20] study the investigation of infrastructure investment performance from the perspective of farmers' satisfaction. They investigate the influencing factors of farmers' satisfaction and draw lessons from domestic and international experience to put forward suggestions to improve the performance of rural infrastructure investment.

Studies related to farmers' satisfaction have focused mainly on the customer satisfaction model and empirical research. For the research based on customer satisfaction, Li and Zeng [21] performed an empirical analysis using CSI-Probit Regression Model on the satisfaction of rural public goods and its influencing factors. They found obvious common characteristics in the same type of city (state), and influencing factors of CSI consist of farmers receiving education, medical accessibility, the income level of farmers, and effective irrigation rate. $\mathrm{Li}$ and $\mathrm{Xu}[22,23]$ built a performance evaluation model and evaluation index system of rural public infrastructure based on the American Customer Satisfaction Index (ACSI). Studies on farmers' satisfaction and influencing factors show that farmers are dissatisfied with the construction of rural infrastructure by the end of 2010 in most areas of China, and farmers are mainly concerned about roads, drinking water, basic education, water conservancy, and medical facilities. On the other hand, it is worth noting that farmers began to pay attention to living infrastructure such as waste disposal facilities and sewage treatment facilities. Kong and Tu [24], Yi et al. [25], Zhang and Wan [26], Wang [27], and Gan and Zhu [28] studied farmers' satisfaction, farmers' demand, and investment willingness and current situation of rural infrastructure construction 
through empirical investigation. Fan and Luo [29] used the structural equation model to analyze 670 questionnaires and found that farmers' satisfaction is positively correlated with income, village type, price of infrastructure, family structure, and sense of superiority compared with neighboring villages. They also argued that the rural infrastructure construction suffers not only from "scarcity" but also from "inequality." Tang et al. [30] and Wang and Zhu [31] launched studies of farmers' satisfaction and its influencing factors based on a survey of 32 villages and towns in Shaanxi Province. The results showed that farmers' satisfaction is significantly affected by rural roads, rural infrastructure, rural healthcare, irrigation facilities, drinking water facilities, and government credit. Moreover, Tang et al. [30] pointed out that farmers' demand for rural public services has a certain level and stage, while farmers' satisfaction has a certain order according to their demand. Han et al. [32] built a custom satisfactionbased quality evaluation index and evaluation system. Existing research on farmers' attitude only stayed at 2010, and there is no further related research after 2010 .

Problems and policy recommendations in the study showed that the main problems in the construction of rural infrastructure consisting of the "top-down" decision-making mechanism cannot meet the real needs of farmers and have incomplete maintenance, imperfect laws and regulations, unclear division of responsibilities, imperfect supervision mechanism, lack of farmers' participation, lack of capital, and lack of investors [33-39]. To solve these problems, researchers suggest establishing a decision-making mechanism to combine "bottom-up" and "top-down" and sound decisionmaking information communication mechanism, improving the decision-making, and supervising the mechanism of rural infrastructure and responsibility mechanism and improving the laws and regulations [21-36], rural infrastructure investment, and financing system innovation [36] and introducing PPP into rural infrastructure [35].

Integrating existing research, considerable research has been performed in relation to farmers' satisfaction and influencing indicators in rural infrastructure. However, no further analysis related to significant indicators exists, such as the reason of their significant impact, influence pattern, measures to improve their performance to help with the improvement of rural infrastructure, and ways to avoid negative effects caused by them. Besides, most existing studies separately focus on farmers' satisfaction, a certain kind of infrastructure, and the farmers' satisfaction under horizontal comparison or vertical comparison. No comprehensive consideration of all rural infrastructure satisfaction, horizontal comparison, and vertical comparison of farmers' satisfaction and farmers' perception of infrastructure charges and other factors exist. On the other hand, there remains a gap ever since 2010, so that we have no understanding of the current situation and farmers' actual demands of rural facilities. Thus, to investigate the current status of rural infrastructure in Sichuan, this paper takes these aforementioned factors into account and plans to achieve further analysis for significant indicators. In this paper, factor analysis and logit regression model were used to analyze farmers' satisfaction and its influencing indicators to know the current situation of rural facilities in Sichuan and prepare for further analysis.

\section{Method}

Several methods to study farmers' satisfaction have been utilized, including analytic hierarchy process, factor analysis, cluster analysis, and CSI. Results calculated by different methods have some differences, but the general trend is basically the same [30]. This paper used factor analysis to extract 15 factors and then used the regression model to study the effects of the 15 factors on farmers' satisfaction.

3.1. Factor Analysis. Factor analysis is a multivariate statistical analysis method that can convert measured variables to a small number of nonrelated comprehensive factors. These comprehensive factors reflect the main information of original measured variables and explain the relationship between measured variables [30]. Specifically, factor analysis studies the condensation of a large number of measured variables to a few factors with the least information loss [40]. In this paper, for as many as 53 indicators, the use of factor analysis to convert indicators into comprehensive factors is necessary. The general form of factor analysis model is

$$
\begin{aligned}
X_{i}=\mu+a_{i 1} F_{i 1}+a_{i 2} F_{i 2}+\cdots+a_{i n} F_{i n}+ & \varepsilon_{i} \\
& (i=1,2, \ldots, p) .
\end{aligned}
$$

Among them, $X_{i}$ is a random observed variable, representing farmers' personal feature and their judgment of infrastructure; $F_{i}$ is a common factor; $a_{i j}(i=1,2, \ldots, p)$ is factor load; and $\varepsilon_{i}$ is special factor part not included in common factors.

3.2. Logit Regression Model. The dependent variable is the overall satisfaction of farmers with the rural facilities and is divided into two categories: "satisfaction" and "dissatisfaction." Statistical methods that can be used to handle categorical dependent variables include discriminant analysis, probit analysis, logit regression model, and log-linear model. Logit regression analysis is an ideal model for analyzing individual decision behavior and is widely used in the analysis of influencing factors. Logit regression analysis is divided into binary logistic regression analysis, where the dependent variables can only be 1 or 0 , and multinomial logistic regression analysis, where the dependent variables can take more than two values. In this paper, the dependent variable is divided into two categories, so the binary logistic regression model is adopted. Variables do not have to meet the normal distribution or equal variance in logit model. The probability of occurrence for specimen is $P(y=1$ | $\left.x_{i}\right)=p_{i}$, and two probability incidents, occurrence and nonoccurrence, are recorded as the following two formulas:

$$
\begin{aligned}
p_{i} & =\frac{1}{1+e^{-\left(\alpha+\sum_{i=1}^{m} \beta_{i} x_{i}\right)}}=\frac{e^{\alpha+\sum_{i=1}^{m} \beta_{i} x_{i}}}{1+e^{\alpha+\sum_{i=1}^{m} \beta_{i} x_{i}}} \\
1-p_{i} & =1-\frac{e^{\alpha+\sum_{i=1}^{m} \beta_{i} x_{i}}}{1+e^{\alpha+\sum_{i=1}^{m} \beta_{i} x_{i}}}=\frac{1}{1+e^{\alpha+\sum_{i=1}^{m} \beta_{i} x_{i}}} .
\end{aligned}
$$


$p_{i}$ represents the probability of occurrence of events in observation; $1-p_{i}$ represents the probability of nonoccurrence of events in observation; both are nonlinear functions formed only by variable $x_{i}$.

$p_{i} /\left(1-p_{i}\right)$ represents the ratio of the probability occurrence and the nonoccurrence of the event, named occurrence ratio. The logarithmic transformation to the occurrence ratio produces the linear model of the logit regression model.

$$
\ln \left(\frac{p_{i}}{1-p_{i}}\right)=\alpha+\sum_{i=1}^{m} \beta_{i} x_{i} .
$$

\section{Empirical Study}

4.1. Evaluation Index Selection. On the basis of existing research, we selected evaluation indices related to several types of facilities and several aspects, such as rural roads, drinking water, sewage treatment, renovation and construction of public toilets, village planning and renovation, electricity and communication signal facilities, renovation of fuel and kitchen, irrigation facilities, healthcare facilities, cultural and entertainment facilities, educational facilities, farmers' satisfaction, satisfaction compared to that five years ago and neighboring villages, and feeling of fees. At the same time, farmers' individual characteristics indices, such as gender, age, region, education, family population, family structure, family income, source of income, village type, and distance from the village to county, were also included. Finally, 53 indices were selected. The sources and specific content of the evaluation index are shown in Tables 1 and 4.

Farmers' individual characteristics indices are important parts of the questionnaire. We can understand the regional differences of rural infrastructure construction in Sichuan Province, the economic conditions of farmers, and the views and needs of different ideological level on the construction of rural infrastructure through the study of farmers' individual characteristics. Rural roads, drinking water, sewage treatment, renovation and construction of public toilets, village planning and renovation, electricity and communication signal facilities, renovation of fuel and kitchen, irrigation facilities, healthcare facilities, cultural and entertainment facilities, and educational facilities are contents of rural infrastructure. The purpose of this study is to fully understand the situation of rural infrastructure construction in Sichuan. Therefore, this study takes into account the above-mentioned infrastructure and aims to understand the construction of various types of rural infrastructure in Sichuan.

Satisfaction Compared to That Five Years Ago. it can reflect the construction of rural infrastructure in Sichuan Province in the past 5 years through farmers' satisfaction compared to that five years ago.

Satisfaction Compared to Neighboring Villages. It shows differences in infrastructure construction between adjacent villages and also studies the psychology of farmers to discuss the influence of comparative superiority on peasant household.

Feeling of Fees. It helps to understand the charges of infrastructure in the process of using and understand the economic
TABLE 1: Index source.

\begin{tabular}{|c|c|}
\hline Index & Source \\
\hline Region & {$[18]$} \\
\hline Gender & $\begin{array}{c}{[18,20,21,26,} \\
30,31]\end{array}$ \\
\hline Age & $\begin{array}{c}{[18,20,21,24,} \\
26,30,31]\end{array}$ \\
\hline Family top education & $\begin{array}{c}{[18,20,24,26} \\
30,31]\end{array}$ \\
\hline Family size & {$[20,26,30,31]$} \\
\hline Family structure & [29] \\
\hline Village type & {$[18,29,31]$} \\
\hline Annual income & $\begin{array}{c}{[18,20,21,26} \\
30,31]\end{array}$ \\
\hline Source of income & {$[18,24]$} \\
\hline Distance from village to county & {$[18,21,29,31]$} \\
\hline Road & {$[21,25-28,30]$} \\
\hline Drinking water & {$[25-28,30,31]$} \\
\hline Sewage treatment & [25-27] \\
\hline Renovation of public toilets & [27] \\
\hline Village planning and reconstruction & {$[27]$} \\
\hline Electricity and communication signal & {$[26,27]$} \\
\hline Renovation of fuel and kitchen & [27] \\
\hline Irrigation facilities & $\begin{array}{l}{[21,24,25,27,} \\
28,30]\end{array}$ \\
\hline Health facility & {$[21,25,26,28]$} \\
\hline Culture and entertainment & {$[26,28,30]$} \\
\hline Education facilities & $\begin{array}{l}{[21,25,26,28,} \\
30]\end{array}$ \\
\hline $\begin{array}{l}\text { Infrastructure compared with that } 5 \text { years } \\
\text { ago }\end{array}$ & {$[29,31]$} \\
\hline $\begin{array}{l}\text { Infrastructure compared with } \\
\text { neighboring villages }\end{array}$ & {$[29,31]$} \\
\hline Infrastructure charges & {$[22,24,29]$} \\
\hline Total satisfaction & {$[22,29,30]$} \\
\hline
\end{tabular}

burden that rural infrastructure construction brings to peasant household.

Total Satisfaction. It reflects the satisfaction of rural households to the construction of rural infrastructure directly, at the same time as the dependent variable in logistic regression analysis. It is essential in the research index.

4.2. Data Sources. This paper is based on the National Natural Science Foundation of China Youth Fund Project "Contribution of Rural Infrastructure Investment and the Degree of Satisfaction of the Government Role Orientation" (71301151), and data were obtained under the organization of home research with the help of students from the Engineering Management Department of Chengdu University of Technology. To ensure the validity and authenticity of the data, and to guarantee that interviewees can understand the questions well, the research group regarded students 
TABLE 2: Basic information of interviewees.

\begin{tabular}{lc}
\hline Factor & Proportion \\
\hline Gender & \\
Female & $43.6 \%$ \\
Male & $56.4 \%$ \\
Family size & \\
Less than 4 people & $30.4 \%$ \\
4 people & $30 \%$ \\
5 people & $25.8 \%$ \\
More than 5 people & $13.8 \%$ \\
Age & \\
Less than 20 years & $15 \%$ \\
From 20 to 30 years & $69.1 \%$ \\
From 30 to 40 years & $5.2 \%$ \\
From 40 to 50 years & $8.2 \%$ \\
From 50 to 60 years & $2.1 \%$ \\
Over 60 years & $0.4 \%$ \\
Family top education & \\
Primary school & $0.8 \%$ \\
Junior high school & $7.6 \%$ \\
High school & $13.9 \%$ \\
Bachelor's & $75.6 \%$ \\
Master's & $1.7 \%$ \\
Doctorate & $0.4 \%$ \\
Annual income & \\
Less than 50,000 Yuan & $67.5 \%$ \\
From 50,000 to 100,000 Yuan & $22.8 \%$ \\
From 100,000 to 200,000 Yuan & $6.8 \%$ \\
Over 200,000 Yuan & $2.9 \%$ \\
\hline
\end{tabular}

from rural area as preinterviewers. A meeting was held to investigate students' opinions of rural infrastructure and guarantee the validity of questionnaires that students were responsible for. A total of 300 questionnaires were issued; 243 valid questionnaires were recovered, with an effective recovery rate of $81 \%$. The questionnaire covers 23 cities in Sichuan Province, encompassing a wide range of regional representation. A total of 106 women and 137 men were interviewed, accounting for $43.6 \%$ and $56.4 \%$, respectively. The basic situation of all investigated objects is shown in Table 2.

4.3. Farmers' Satisfaction Factor Analysis. The Likert scale was used for the questionnaire analysis (e.g., $1=$ very dissatisfied; 3 = dissatisfied; 5 = moderate; 7 = satisfied; and 9 = very satisfied). The definition of variables, except for 5 , is established with linear interpolation method. Parts of variables are shown in Table 3.

SPSS software was used to analyze the data. The original data are normalized to eliminate the difference in magnitude and dimension. To ensure validity of the questionnaire, the validity and construct validity of the questionnaire were tested by Cronbach's coefficient. The coefficient of the questionnaire data was 0.927 , indicating that the questionnaire is reliable.
Factor analysis showed that the KMO statistic was 0.775 , and the $P$ value was 0 ; hence, the test results were significant. These data indicated that questionnaire data had a certain correlation, indicating its suitability for factor analysis. Factor analysis showed that the extractions of 53 indicators are all above 0.4 , and all these extractions of indicators, except for family structure and the average annual income, reached a degree of 0.5 , demonstrating that most of the information in the representation variable is extracted by factors. Using the principal component method to extract 16 factors, the researchers determined that their feature values are greater than 1 . The component matrix is rotated using the method of maximum variance orthogonal rotation because the initial loading structure is not clear. Moreover, the load of the village type index is less than 0.4 on the common factor, and factor analysis is carried out again after the variable is deleted. Fifteen factors were extracted after the moveout-of-village type. The component matrix is rotated using maximum variance orthogonal rotation, and the loads on the common factors are all above 0.4 , whereas the total variance explained is $71.2 \%$. The rotated component matrix is shown in Table 4.

The distribution of factor indices is shown in Table 4 . Index situation and factor naming are shown in Table 5. Table 5 shows that horizontal comparison indices (perceptual evaluation index compared with neighboring villages) are concentrated mainly in factor $F 1$, and the longitudinal comparison index is distributed mostly in the factor of this kind of infrastructure. At the same time, rural infrastructure charge perception indices are concentrated in factors $F 2$ and $F 11$ and personal and village characteristics are concentrated in factors $F 13, F 14$, and $F 15$. Farmers' satisfaction on rural infrastructure and vertical comparison index (perception evaluation index compared with that five years ago) are relatively concentrated in the infrastructure factor.

The comprehensive score of each index was obtained based on the analysis of the factor score coefficient table, and the scores of the absolute values are normalized to obtain the weight of each index. According to the results of the questionnaire, the overall evaluation score of rural infrastructure construction satisfaction was 4.84 .

4.4. Logit Regression Analysis Based on Factor Analysis. The dependent variable of this paper is the total satisfaction of rural households with the infrastructure construction, which is divided into two categories: "satisfaction" and "dissatisfaction." Logit regression analysis was used to analyze 15 factors. The results of the omnibus test are shown in Table 6, and the results of Hosmer and Lemeshow test are shown in Table 7. Test results show that the model is very significant, and dependent variables had no significant difference with predicted values. The model has a $-2 \ln$ likelihood of 237.764, while the observation correct percentage of the model reached $75.3 \%$, indicating that the fitting effect of the model is ideal. Estimation results of the model are shown in Table 8.

4.5. Discussion. According to the Wald value in Table 8, factors with significant effect on the satisfaction of farmers 
TABLE 3: Variable definition.

\begin{tabular}{|c|c|}
\hline Variable & Variable definition \\
\hline Total satisfaction & $0=$ dissatisfied, $1=$ satisfied \\
\hline Gender & $1=$ female, $9=$ male \\
\hline Age & $\begin{array}{l}1=\text { over } 60 \text { years, } 2.6=\text { from } 50 \text { to } 60 \text { years, } 4.2=\text { from } \\
40 \text { to } 50 \text { years, } 5.8=\text { from } 30 \text { to } 40 \text { years, } 7.4=\text { from } 20 \\
\text { to } 30 \text { years, } 9=\text { less than } 20 \text { years }\end{array}$ \\
\hline Family top education & $\begin{array}{l}1=\text { primary school, } 2.6=\text { junior high school, } 4.2=\text { high } \\
\text { school, } 5.8=\text { Bachelor's, } 7.4=\text { Master's, } 9=\text { Doctorate }\end{array}$ \\
\hline Family size & $\begin{array}{l}1=\text { more than } 5 \text { people, } 3.67=5 \text { people, } 6.33=4 \text { people, } \\
9=\text { less than } 4 \text { people }\end{array}$ \\
\hline Family structure & $1=$ ordinary family, $5=$ party family, $9=$ cadre family \\
\hline Annual income & $\begin{array}{l}1=\text { less than } 50,000 \text { Yuan, } 3.67=\text { from } 50,000 \text { to } 100,000 \\
\text { Yuan, } 6.33=\text { from } 100,000 \text { to } 200,000 \text { Yuan, } 9=\text { over } \\
200,000 \text { Yuan }\end{array}$ \\
\hline Village type & $\begin{array}{l}1=\text { ordinary village, } 3.67=\text { township resident, } 6.33= \\
\text { combination of urban and rural areas, } 9=\text { both } \\
\text { township resident and a combination of urban and } \\
\text { rural areas }\end{array}$ \\
\hline Distance from village to county & $\begin{array}{l}1=\text { more than } 100 \mathrm{~km}, 2.6=\text { from } 50 \text { to } 100 \mathrm{~km}, 4.2= \\
\text { from } 30 \text { to } 50 \mathrm{~km}, 5.8=\text { from } 20 \text { to } 30 \mathrm{~km}, 7.4=\text { from } 10 \\
\text { to } 20 \mathrm{~km}, 9=\text { less than } 10 \mathrm{~km}\end{array}$ \\
\hline Infrastructure satisfaction & $\begin{array}{l}1=\text { very dissatisfied, } 3=\text { dissatisfied, } 5=\text { moderate, } 7= \\
\text { satisfied, } 9=\text { very satisfied }\end{array}$ \\
\hline Infrastructure compared that with 5 years ago & $\begin{array}{l}1=\text { worse, } 3.67=\text { almost no change, } 6.33=\text { having } \\
\text { certain improvement, } 9=\text { much better }\end{array}$ \\
\hline $\begin{array}{l}\text { Village infrastructure compared with neighboring } \\
\text { villages }\end{array}$ & $\begin{array}{l}1=\text { one of the worst, } 3=\text { worse than medium, } 5= \\
\text { medium, } 7=\text { better than medium, } 9=\text { one of the best }\end{array}$ \\
\hline Infrastructure charges & $\begin{array}{l}1=\text { no charge, } 2.6=\text { very cheap, } 4.2=\text { cheap, } 5.8= \\
\text { suitable, } 7.4=\text { expensive, } 9=\text { very expensive }\end{array}$ \\
\hline
\end{tabular}

include $F 1, F 6, F 8, F 9, F 12, F 10, F 5$, and $F 7$, and their effect size is decreased in turn.

F1 represents the horizontal comparison factor, which reflects mainly the evaluation of infrastructure compared with neighboring villages with a significant level of $1 \%$. It has a very significant positive effect on farmers' satisfaction in all factors. Specifically, the higher the horizontal comparison, the higher the total satisfaction. This result is consistent with the result of Fan and Luo [29].

F6 refers to the factor of renovation and construction of public toilets, which has a significance level of $1 \%$. It has a positive effect on rural infrastructure satisfaction, which means that the more satisfied the farmers are with public toilets construction and renovation, the more satisfied they are with the overall rural infrastructure. Public toilets construction and renovation are related to the overall health condition and village image, and the positive effect shows that farmers pay attention to the living conditions and environment.

F8 represents the renovation of fuel and kitchen factor, which passed the $1 \%$ significant level test and also has a positive effect on rural infrastructure satisfaction, indicating that the better constructed the fuel and kitchen renovation is, the more satisfied farmers are with the overall infrastructure. Although the rural economy improved significantly, the main fuel is still coal or firewood in many rural areas, and natural gas is not entirely popular in rural areas. Fuel and kitchen renovation can reduce waste gas pollution caused by the rural kitchen and bring convenience to farmers. The effect of this factor on farmers' satisfaction shows that farmers pay attention to the improvement of the living environment and life quality.

F9 represents healthcare facilities, which reached the $1 \%$ level in the significance test, and has a positive effect on farmers' satisfaction, indicating that the more perfect health facilities and better medical conditions significantly contribute to farmers' satisfaction of rural infrastructure.

$F 12$ is a reflection of the income of farmers, with a $5 \%$ level of significance test. It has a positive effect on farmers' satisfaction: the higher the household annual income and the more income sources, the higher the rural infrastructure satisfaction evaluation.

$F 10$ is a reflection of the village planning and renovation, with a 5\% significance level. It has a positive effect on farmers' satisfaction, consistent with $F 6$, indicating that farmers pay attention to the change of living environment and propose requirements of living conditions.

F5 comprehensively represents road, electricity, and communication signals facilities, with a 5\% significance level of testing. It also has a positive effect on farmers' satisfaction. In recent years, the government has increased its investment 


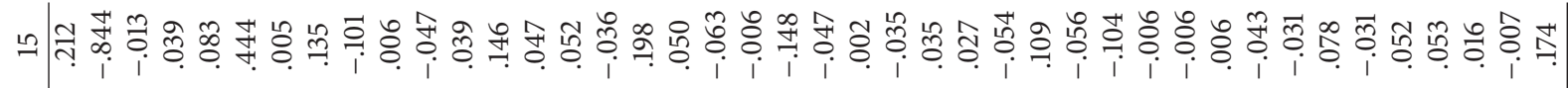

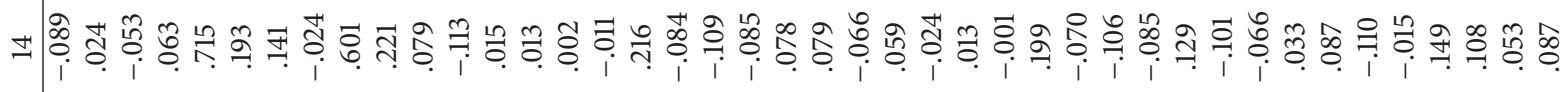

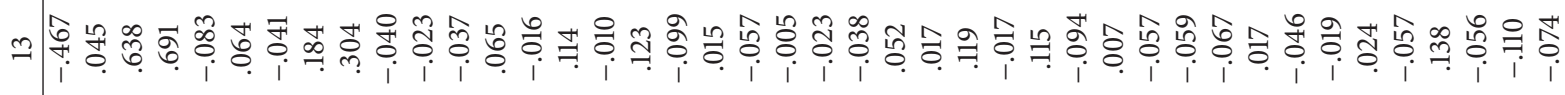

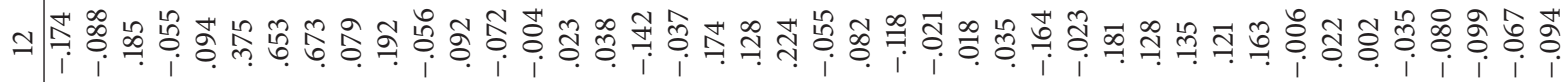

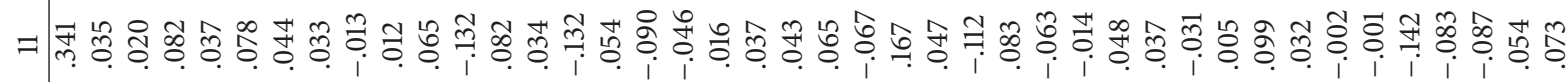

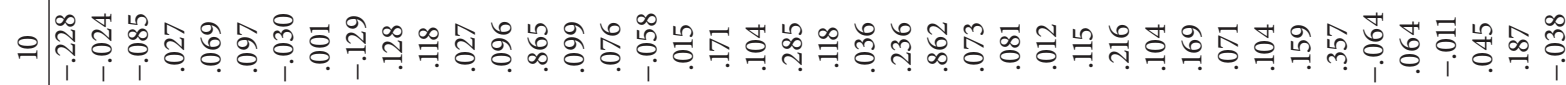

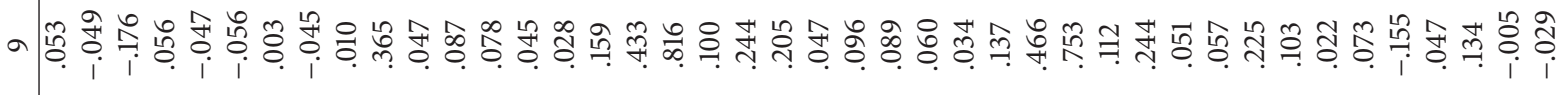

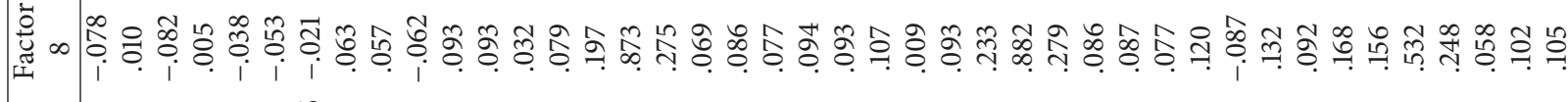

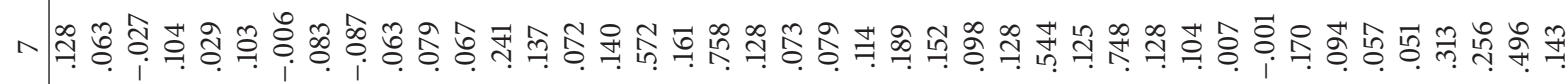

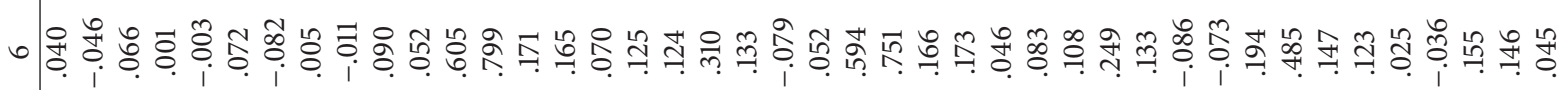

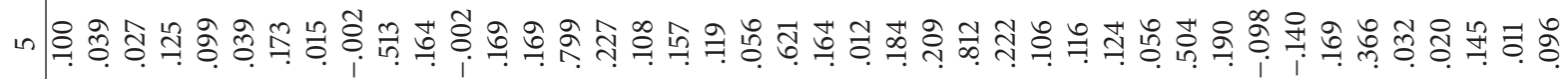

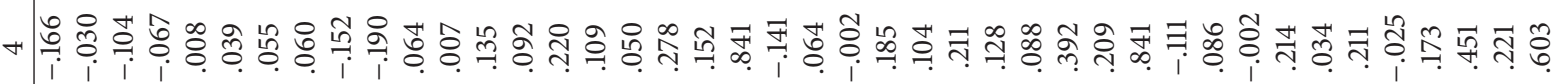

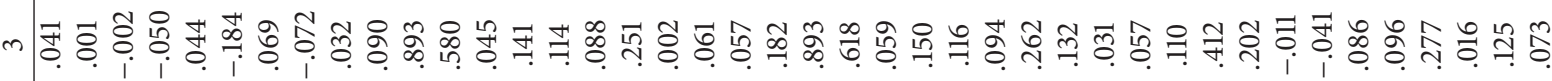

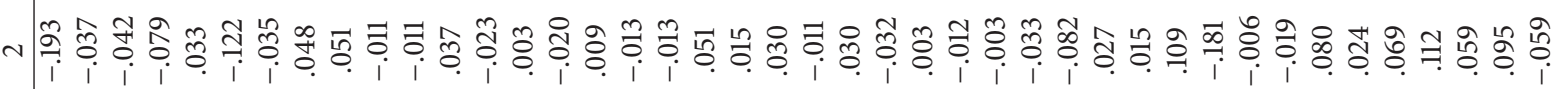

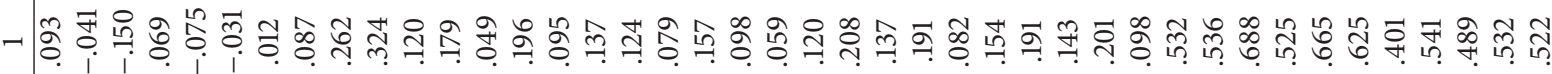

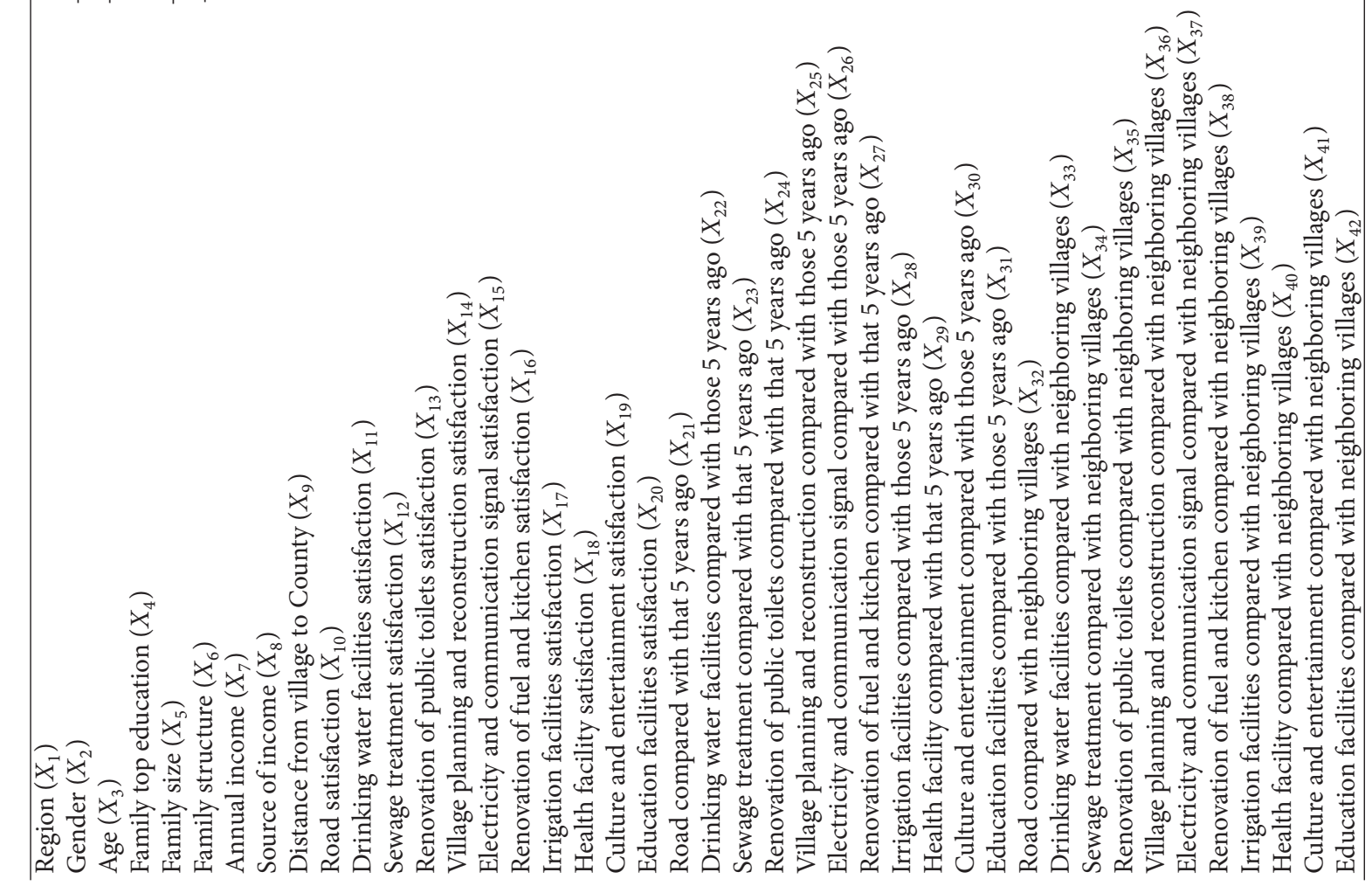




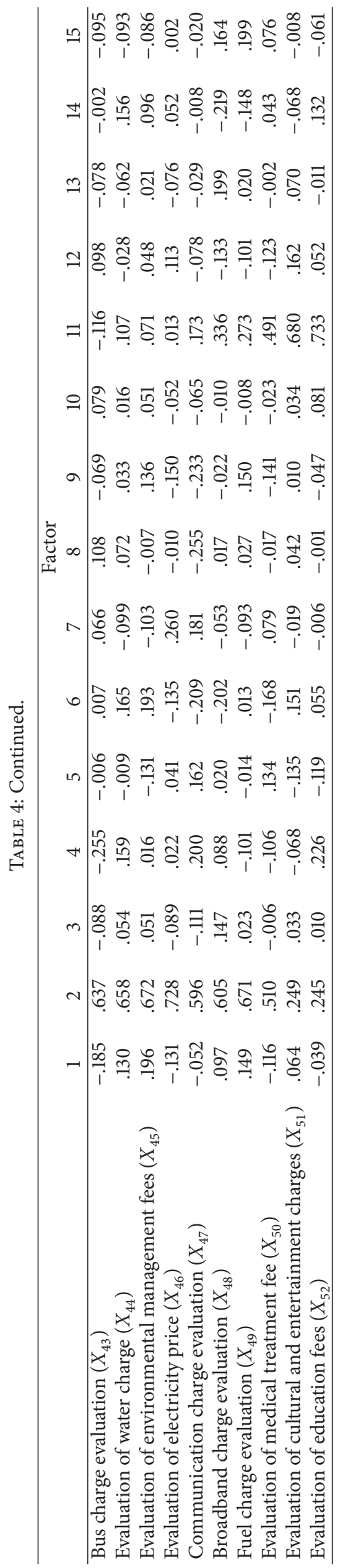


TABLE 5: Indicators in each factor.

\begin{tabular}{lr}
\hline Factor & Index \\
\hline$F_{1}$ (horizontal comparison) & $X_{32}, X_{33}, X_{34}, X_{35}, X_{36}, X_{37}, X_{39}, X_{40}, X_{41}$ \\
$F_{2}$ (charge factor) & $X_{43}, X_{44}, X_{45}, X_{46}, X_{47}, X_{48}, X_{49}, X_{50}$ \\
$F_{3}$ (drinking water facilities) & $X_{11}, X_{22}, X_{23}$ \\
$F_{4}$ (education) & $X_{20}, X_{31}, X_{42}$ \\
$F_{5}$ (road, electric and communication signal) & $X_{10}, X_{15}, X_{21}, X_{26}$ \\
$F_{6}$ (renovation of public toilets) & $X_{12}, X_{13}, X_{24}$ \\
$F_{7}$ (irrigation facilities, culture and entertainment) & $X_{17}, X_{19}, X_{28}, X_{30}$ \\
$F_{8}$ (renovation of fuel and kitchen) & $X_{16}, X_{27}, X_{38}$ \\
$F_{9}$ (health facilities) & $X_{18}, X_{29}$ \\
$F_{10}$ (village planning and reconstruction) & $X_{14}, X_{25}$ \\
$F_{11}$ (charge factor) & $X_{51}, X_{52}$ \\
$F_{12}$ (income situation) & $X_{7}, X_{8}$ \\
$F_{13}$ (area, age, and family highest degree) & $X_{1}, X_{3}, X_{4}$ \\
$F_{14}$ (family size and distance from village to county) & $X_{5}, X_{9}$ \\
$F_{15}$ (gender and family structure) & $X_{2}, X_{6}$ \\
\hline
\end{tabular}

TABLE 6: Omnibus test of model coefficients.

\begin{tabular}{lccc}
\hline & Chi-square & Df. & Sig. \\
\hline Step 1 & & & \\
Step & 81.505 & 15 & 0.000 \\
Block & 81.505 & 15 & 0.000 \\
Model & 81.505 & 15 & 0.000 \\
\hline
\end{tabular}

TABle 7: Hosmer and Lemeshow test.

\begin{tabular}{lccc}
\hline Step & Chi-square & Df. & Sig. \\
\hline 1 & 10.818 & 8 & 0.212 \\
\hline
\end{tabular}

TABLE 8: Model estimation results.

\begin{tabular}{lcc}
\hline Variable & Parameter & Wald \\
\hline $\ln \left(F_{1}\right)$ & $1.073^{* * *}$ & 27.497 \\
$\ln \left(F_{2}\right)$ & -0.091 & 0.292 \\
$\ln \left(F_{3}\right)$ & 0.214 & 1.590 \\
$\ln \left(F_{4}\right)$ & 0.026 & 0.027 \\
$\ln \left(F_{5}\right)$ & $0.398^{* *}$ & 6.053 \\
$\ln \left(F_{6}\right)$ & $0.643^{* * *}$ & 11.778 \\
$\ln \left(F_{7}\right)$ & $0.322^{*}$ & 3.629 \\
$\ln \left(F_{8}\right)$ & $0.570^{* * *}$ & 11.302 \\
$\ln \left(F_{9}\right)$ & $0.473^{* * *}$ & 7.763 \\
$\ln \left(F_{10}\right)$ & $0.407^{* *}$ & 5.969 \\
$\ln \left(F_{11}\right)$ & 0.020 & 0.015 \\
$\ln \left(F_{12}\right)$ & $0.467^{* *}$ & 6.347 \\
$\ln \left(F_{13}\right)$ & -0.247 & 2.246 \\
$\ln \left(F_{14}\right)$ & 0.184 & 1.383 \\
$\ln \left(F_{15}\right)$ & 0.043 & 0.069 \\
Constant & $0.856^{* * *}$ & 23.710 \\
\hline
\end{tabular}

Note. $*, * *$, and $* * *$, respectively, represent the significant level of $10 \%$, $5 \%$, and $1 \%$.

in rural roads, resulting in their significant improvement. However, judging from the results of this analysis, rural roads construction still does not meet farmers' expectations, implying that the government should continue to adhere to the construction of rural roads. With the improvement of the economic level of the rural people, an increasing number of families begin to own electrical appliances, demanding higher power supply and telecommunications signals.

F7 comprehensively reflects irrigation facilities and cultural and entertainment facilities. It has a significant level test of $10 \%$ and also has a positive effect on farmers' satisfaction. Similar to the rural roads construction, farmland irrigation equipment has received strong support from the government in recent years but does not meet the needs of farmers. A need to continue to adhere to the construction of irrigation facilities still exists. The positive effect of cultural and entertainment facilities shows that people care about their life quality.

The top three factors that affect farmers' satisfaction are "horizontal comparison," "renovation and construction of public toilets," and "renovation of fuel and kitchen." The horizontal comparison factor ranks in the first place, which coincides with the research of Fan and Luo [29]. This shows that there still exists the phenomenon of rural infrastructure construction that is not only "suffering from poverty" but also "suffering from uneven." To some extent, this unequal gap grows with the increase of time and the continuous construction of rural infrastructure. "Renovation and construction of public toilets" and "renovation of fuel and kitchen" rank second and third, respectively, indicating that they both have a very significant influence on farmers' satisfaction. Wang [27] found that farmers' satisfaction degree with the renovation and construction of public toilets of Guangdong province was only 0.35 in 2009 , which is nearly half the average satisfaction level, and the satisfaction degree with renovation of fuel and kitchen of Guangdong province was only 0.29 in 2009 which is $58.54 \%$ below average. That study indicated that renovation of rural public toilets and the renovation of kitchen fuel in Guangdong province were not optimistic in 2009. Results of Wang [27] show that farmers were more satisfied with production facilities, such as roads, telecommunications, electricity, and small water conservancy but less satisfied with living facilities, such as 
sewage treatment, renovation and construction of public toilets, and renovation of fuel and kitchen. Our finding is consistent with Wang's research.

It is worth noting that Table 8 shows that farmers are focusing on living infrastructure rather than production infrastructure which has always been the focus of attention of farmers in existing research. Tang et al. [30] pointed out that the farmers' satisfaction of rural public service investment is mainly influenced by rural roads, rural basic education, rural medical treatment, irrigation and water conservancy facilities, and drinking water facilities in 2005. Gan and Zhu [28] found that farmers from resourced area of Shanxi, Shaanxi, and Mongolia expect private capital to be used in investment in roads, medical care, and education in 2010. Fan and Luo [29] pointed out that farmers' satisfaction is mostly influenced by the superiority compared with other villages, followed by rural infrastructure prices, family structure, distance from village to county, growth of per capita income, gap between communication supply and demand, and village type, and so on. Kong and Tu [24] found that the most urgent needs of farmers in Fujian province were infrastructure for farmland, water conservancy facilities, roads, medical and health conditions, education, and other infrastructure in 2005. Yi et al. [25] find that what farmers of Sichuan need most are roads, irrigation, drinking water, schools, and clinics in 2005. However, according to the results of this study, health facility, roads, electricity, communications, electricity and communication signal, and irrigation facilities have significant effects on farmers satisfaction of Sichuan Province, but their influence rankings are relatively backward except health facility, and the effects of drinking water facilities, educational facilities, infrastructure charges, and sewage treatment facilities on the satisfaction of farmers were less significant. Tang et al. [30] pointed out that farmers' demand for rural public has a certain level and different phases, while farmers' satisfaction has a certain order according to their demand. That is to say, farmers' satisfaction and demand vary according to regions, economic conditions, and infrastructure construction. Since most of the studies have been done for a long time and not for Sichuan Province, results of this paper are quite different from those of the existing literatures. With continuous improvement of rural infrastructure construction, rural roads, education, and health infrastructure can basically meet farmers' needs. Farmers' attention to rural infrastructure has gradually shifted from production infrastructure to living infrastructure. At the same time, with the development of rural economy and the increase of government investment, rural infrastructure charges no longer bring economic burden to farmers. Sewage treatment facilities are also related to the living environment and health status of rural areas, such as public toilets and construction of healthcare facilities, but they do not have significant effect on farmers' satisfaction. Although farmers pay attention to living environment and health status, their understanding of rural environmental pollution is insufficient, indicating the absence of a good understanding of the hazardous effects of domestic sewage to environment and health. Publicity and training should be increased to help farmers become fully aware of the pollution sources and consequences of rural environmental pollution and to appeal to everyone to work together to improve the ecological environment in rural areas.

Based on Table 8 , this study finds that the regions, family size, age, and family top education have little influence on farmers' satisfaction. This result is basically consistent with the results of Tang et al. [30] and Fan and Luo [29]. Since the study was carried out only in Sichuan, where regional differences are not obvious, the regional factor has little influence on farmers' satisfaction. Family structure, distance between villages, and village type have little influence on farmers' satisfaction, which is inconsistent with the results of Fan and Luo [29]. The reason of this difference may be the great improvement of farmers' collective literacy with the development of rural. The ideological differences between ordinary families and cadres, families, and party members have narrowed. On the other hand, infrastructure of ordinary villages and villages far from the county has also been well improved under continuous construction of the rural infrastructure.

According to the above analysis, factors that affect satisfaction of farmers are represented mainly by the rural living infrastructure, confirming the hierarchy and phase of farmers' demand for rural public services and order of their satisfaction proposed by Tang et al. [30]. Hence, the demand for basic facilities related to production can be considered as having been basically met, and farmers are beginning to require better living environment, cultural entertainment, and other living-related aspects. Farmers' demand for rural infrastructure is no longer limited to meeting the needs of life and production but now includes the requirement of living infrastructure.

\section{Conclusion}

This paper conducted a comprehensive investigation of the situation of rural infrastructure from the perspective of farmers' satisfaction. Factor analysis and logit regression model were used to analyze farmers' satisfaction. The overall satisfaction score of farmers in terms of infrastructure was dissatisfied (4.84 points), indicating that the demand for infrastructure of farmers has not been satisfied, and many problems still need to be addressed in the construction of rural infrastructure. Farmers' satisfaction is affected mainly by the horizontal comparison factor, road facilities, electricity and communication signal facilities, public toilets renovation, irrigation facilities, cultural and entertainment facilities, fuel and kitchen renovation, village planning, medical facilities, and farmers' income situation. Area, age, family top education, family size, and distance from village to county have certain effects on the satisfaction of the farmers, but the effects are limited. Drinking water facilities, sewage treatment facilities, educational facilities, charges, gender, and family structure have little effect on farmers' satisfaction.

Farmers' demand for rural infrastructure is transitioning from production to livelihood. Thus, the government needs to proceed from the actual situation in rural areas and take into account the real needs of farmers to promote the development of rural economy, improve the living standards of farmers, and enable rural infrastructure to truly meet users' demands. 
This paper studies the present situation of the construction of rural infrastructure in Sichuan Province and discusses the construction of various types of rural infrastructure and farmers' views and needs comprehensively. It lays a foundation for further research on development of rural infrastructure construction and farmers' demands and provides a theoretical basis for policy makers. Indices in this research are derived from previous studies, most of which are old and are aimed at other provinces. Therefore, these indices cannot reflect the current rural infrastructure situation of Sichuan Province. It is hoped that index could get further adjustment after this round of research, so that a comprehensive index system could be established to evaluate the current situation of rural infrastructure construction in Sichuan Province.

Our next step is a further analysis based on this paper to achieve further studies on significant factors and conduct another investigation based on this survey.

Research methods of this paper are also applicable to other countries to study present situation of the construction and farmers' satisfaction assessment of rural facilities, but appropriate adjustments should be made accordingly. The construction of rural infrastructure varies from place to place, and the construction effects are different under different national conditions and different construction modes, so the applicability of the conclusions of this study in other countries still needs further discussion.

\section{Conflicts of Interest}

The authors declare no conflicts of interest.

\section{Acknowledgments}

The authors appreciate the support from the National Natural Science Foundation of China (Project nos. 51608060 and 71301151) and the Talent Fund of Chengdu University of Technology (Project no. KYGG201303).

\section{References}

[1] L. Gan, L. Shen, and H. Fu, "Study of the infrastructure project evaluation factors based on sustainable development," Тumu Gongcheng Xuebao/China Civil Engineering Journal, vol. 42, no. 11, pp. 133-138, 2009.

[2] L. Shen, Y. Wu, and X. Zhang, "Key assessment indicators for the sustainability of infrastructure projects," Journal of Construction Engineering and Management, vol. 137, no. 6, pp. 441-451, 2011.

[3] P. Bocchini, D. M. Frangopol, T. Ummenhofer, and T. Zinke, "Resilience and sustainability of civil infrastructure: Toward a unified approach," Journal of Infrastructure Systems, vol. 20, no. 2, Article ID 04014004, 2014.

[4] M. A. Boz and I. H. El-Adaway, "Creating a holistic systems framework for sustainability assessment of civil infrastructure projects," Journal of Construction Engineering and Management, vol. 141, no. 2, Article ID 04014067, 2015.

[5] K. Anagnostopoulos and A. Vavatsikos, "Site suitability analysis for natural systems for wastewater treatment with spatial fuzzy analytic hierarchy process," Journal of Water Resources Planning and Management, vol. 138, no. 2, pp. 125-134, 2012.

[6] N. Domingo, "Assessment of the impact of complex healthcare features on construction waste generation," Buildings, vol. 5, no. 3, pp. 860-879, 2015.

[7] J. Zhou and Y. J. Liu, "The method and index of sustainability assessment of infrastructure projects based on system dynamics in China," Journal of Industrial Engineering and Management, vol. 8, no. 3, pp. 1002-1019, 2015.

[8] S. Glick and A. A. Guggemos, "Rethinking WastewaterTreatment Infrastructure: Case Study Using Life-Cycle Cost and Life-Cycle Assessment to Highlight Sustainability Considerations," Journal of Construction Engineering and Management, vol. 139, no. 12, p. A5013002, 2013.

[9] K. Parrish and M. Chester, "Life-Cycle assessment for construction of sustainable infrastructure," Practice Periodical on Structural Design and Construction, vol. 19, no. 1, pp. 89-94, 2014.

[10] B. Reza, R. Sadiq, and K. Hewage, "Emergy-based life cycle assessment (Em-LCA) for sustainability appraisal of infrastructure systems: A case study on paved roads," Clean Technologies and Environmental Policy, vol. 16, no. 2, pp. 251-266, 2014.

[11] Y. Zhi, Z. Yang, X.-A. Yin, P. B. Hamilton, and L. Zhang, "Evaluating and Forecasting the Drivers of Water Use in a City: Model Development and a Case from Beijing," Journal of Water Resources Planning and Management, vol. 142, no. 1, Article ID $04015042,2016$.

[12] S. T. Ariaratnam, K. Piratla, A. Cohen, and M. Olson, "Quantification of Sustainability Index for Underground Utility Infrastructure Projects," Journal of Construction Engineering and Management, vol. 139, no. 12, p. A4013002, 2013.

[13] C. Torres-Machi, V. Yepes, A. Chamorro, and E. Pellicer, "Current models and practices of economic and environmental evaluation for sustainable network-level pavement management," Revista de la Construccion, vol. 13, no. 2, pp. 49-56, 2014.

[14] S. Xu and Y. Wang, "Efficiency measure of rural infrastructure investment in 29 provinces and cities of China," Construction Economy, vol. 2, pp. 112-114, 2010.

[15] S. Xu, "Research on the establishment of investment contribution model of rural infrastructure," Project Management Journal, vol. 25, no. 3, pp. 288-291, 2011.

[16] W. Li, L. Jiang, and J. Hua, "Performance analysis of china's provincial financial support for agriculture based on the three stage DEA model," Journal of Huazhong Agricultural University, vol. 1, pp. 69-77, 2014.

[17] A. Ansar, B. Flyvbjerg, A. Budzier, and D. Lunn, "Does infrastructure investment lead to economic growth or economic fragility? Evidence from China," Oxford Review of Economic Policy, vol. 32, no. 3, pp. 360-390, 2016.

[18] D. Peng, Performance evaluation of rural public investment based on farmers' satisfaction, Shandong Agricultural University, Shandong, China, 2012.

[19] X. Zhang and K. Wang, "Analysis on regional difference of China's rural infrastructure investment," Financial Science, vol. 3, pp. 77-84, 2012.

[20] S. Luo, Small Farmland Water Conservancy Investment Performance Evaluation Based on Farmers' Satisfaction, Hunan Agricultural University, Hunan, China, 2014.

[21] Y. Li and F. Zeng, "Farmers satisfaction of rural public goods supply and its influencing factors," in Research on Quantitative Economic Technology, vol. 8, pp. 3-18, 2008. 
[22] W. $\mathrm{Li}$ and $\mathrm{K} . \mathrm{Xu}$, "Research on farmers satisfaction model and evaluation index establishment of rural public infrastructure," Journal of Second Hubei Education University, vol. 28, no. 5, pp. 74-98, 2011.

[23] W. Li, "Farmers satisfaction evaluation of rural public infrastructure," Journal of Chongqing University, vol. 18, no. 4, pp. 915, 2012.

[24] X. Kong and S. Tu, "Research on the demand preference and influence factors of rural households to public goods in new rural construction-a case study of irrigation and water conservancy facilities," Agricultural Economic Problems, vol. 10, pp. 10-16, 2006.

[25] H. Yi, L. Zhang, D. Hare, and C. Liu, "The relationship between the investment of rural infrastructure and the farmers' investment demands: an empirical analysis of 5 province," China Soft Science, vol. 11, pp. 106-115, 2008.

[26] K. Zhang and M. Wan, "Research on farmers' willingness to invest in the rural infrastructure construction-a case study of henan province," Journal of Zhongnan University of Economics and Law, vol. 5, pp. 36-41, 2009.

[27] C. Wang, "Farmers' willingness to participate in the financing of rural infrastructure construction-a case study," Shanghai Economic Research, vol. 3, pp. 18-26, 2010.

[28] J. Gan and Y. Zhu, "Folk capital access to rural infrastructurebased on the investigation of 31 villages and towns in the resource rich region of Shanxi and Shaanxi," in Exploration of Economic Problems, vol. 11, pp. 153-158, 2011.

[29] L. Fan and Y. Luo, "Influencing factors of farmers' satisfaction to rural infrastructure-based on the structural equation model analysis of 670 questionnaires," Agricultural Economic Problems, vol. 9, pp. 51-59, 2009.

[30] J. Tang, Y. Zhu, and C. Liu, "Analysis of rural public service satisfaction and its influencing factors-based on the survey of 67 villages in 32 towns in shaanxi province," Contemporary Economic Science, vol. 32, pp. 101-116, 2010.

[31] L. Wang and Y. Zhu, "Performance appraisal of rural drinking water supply based on farmers' perception: an analysis of the data from 803 households," Agricultural Technical and Economic, vol. 2, pp. 64-71, 2013.

[32] S. Han, M. J. Chae, H. Hwang, and Y.-K. Choung, "Evaluation of customer-driven level of service for water infrastructure asset management," Journal of Management in Engineering, vol. 31, no. 4, Article ID 4014067, 2015.

[33] Z. Zhang, L. Xia, and L. Zhang, "Thoughts on introducing nongovernmental funds into rural infrastructure construction in China," Rural Economy, vol. 3, pp. 66-68, 2004.

[34] C. Li, "Current problems and countermeasures of rural infrastructure construction," Journal of Shandong Agricultural Administrators College, vol. 23, no. 3, pp. 25-28, 2008.

[35] C. Wang, "Study on PPP model of rural infrastructure governance," Agricultural Economic Problems, vol. 6, pp. 64-67, 2008.

[36] S. Xuan, Research on Decision Making Mechanism of Rural Infrastructure Construction, Nanjing Agricultural University, Nanjing, China, 2010.

[37] Z. Li, H. Liu, and J. Liu, "Study on the Imbalance of Chinas Rural Infrastructure Construction," Geographical Science, vol. 30, no. 6, pp. 839-846, 2010.

[38] Z. Li, Study on the Regulation and Control of Rural Infrastructure in China, Northeast Normal University, Changchun, China, 2011.
[39] W. Kang, "Research on investment and financing system innovation of Chinas Rural Infrastructure," Contemporary Economic Management, vol. 34, no. 9, pp. 91-96, 2012.

[40] W. Li, Application of Multivariate Statistical Analysis [M], Peking University Press, Beijing, China, 2008. 


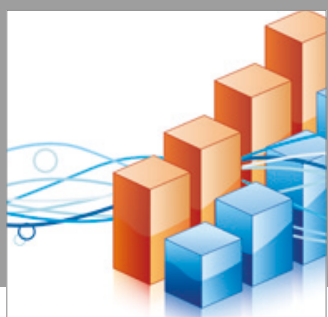

Advances in

Operations Research

vatersals

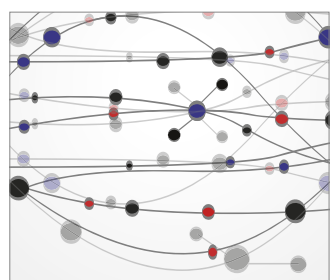

\section{The Scientific} World Journal
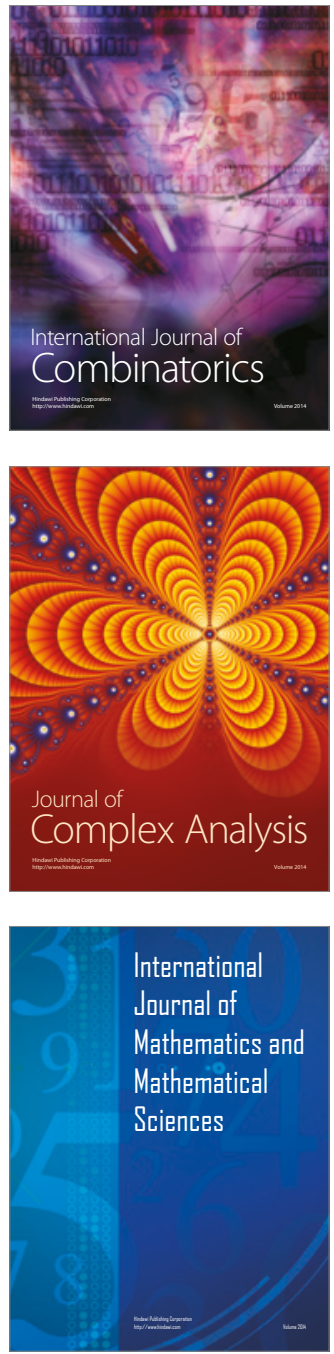
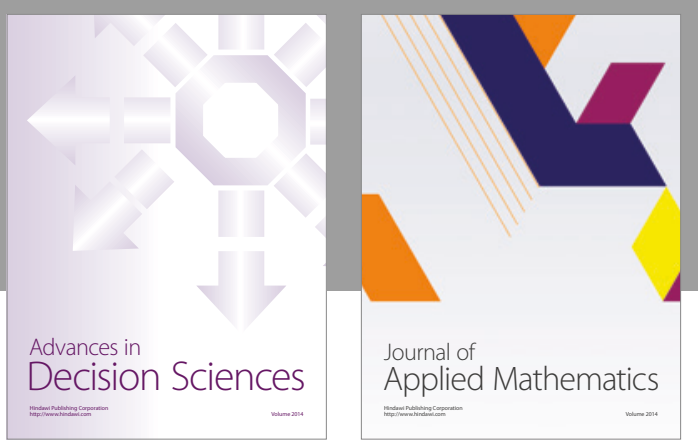

Algebra

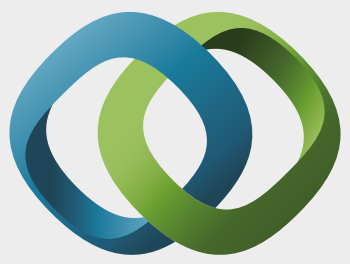

\section{Hindawi}

Submit your manuscripts at

https://www.hindawi.com
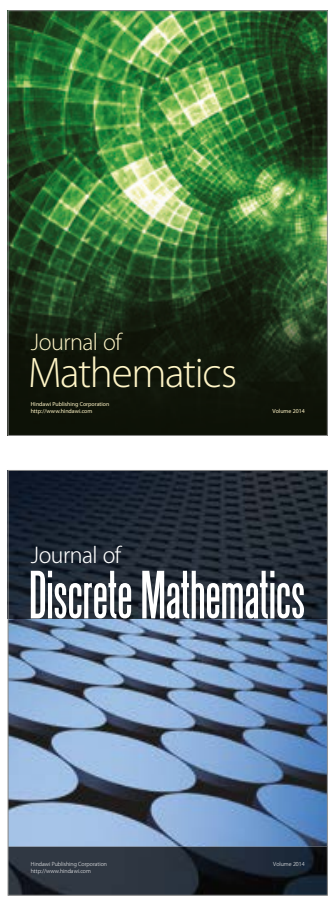

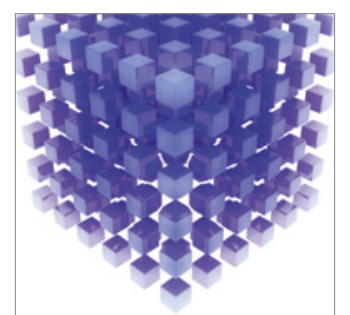

Mathematical Problems in Engineering
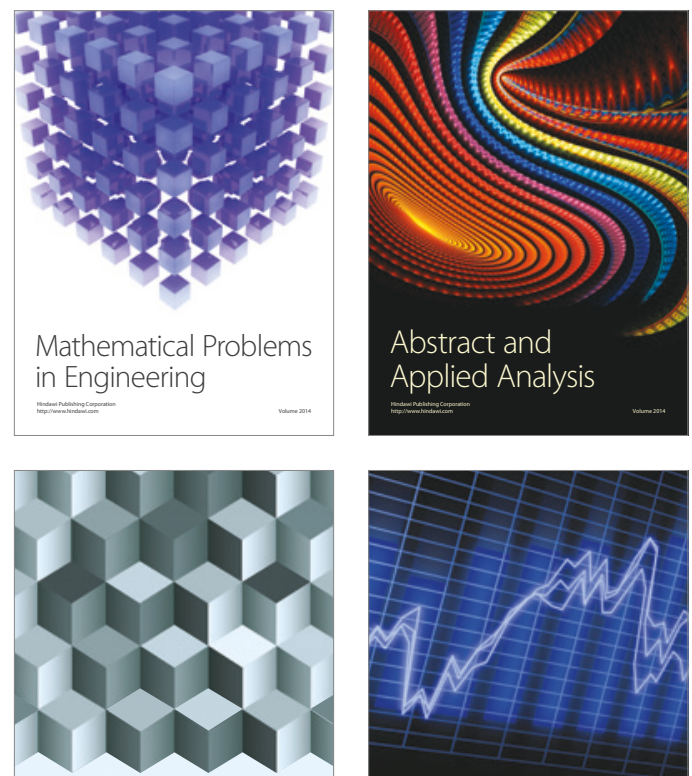

Journal of

Function Spaces

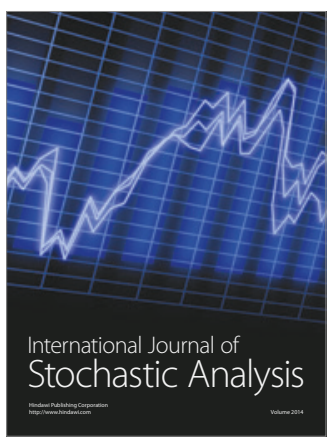

Probability and Statistics
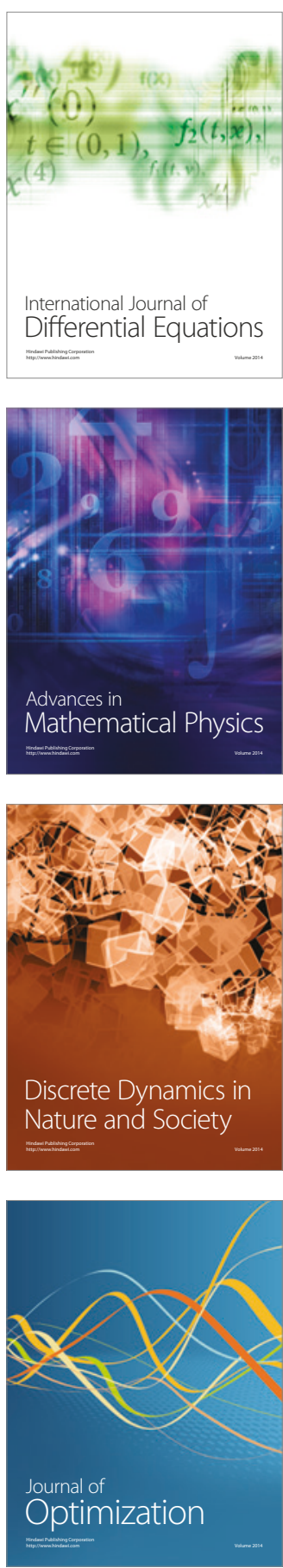